\title{
Acidente ofídico crotálico em equino produtor de plasma escorpiônico na Fazenda São Joaquim/SP - relato de caso
}

Camila Costa Cason ${ }^{[a]}$, Aymara Eduarda de Lima ${ }^{[a]}$, Thayna Kikuchi Monteiro ${ }^{[a]}$, Dácio de Castro Dias ${ }^{[b]}$, Michele Cristiane de Camargo ${ }^{[b]}$, Mônica Freitas Silva ${ }^{[b]}$, Rafaela Suemi Araki Bueno ${ }^{[a]}$, Liliane Ramos da Rocha Pereira ${ }^{[a]}$, Cesar Graner ${ }^{[b]}$, Ronaldo Azevedo Ferreira[b]

\footnotetext{
[a] Universidade Anhembi Morumbi (UAM), São Paulo, SP, Brasil

${ }^{[b]}$ Iinstituto Butantan, São Paulo, SP, Brasil
}

*Autor correspondente

e-mail: dacio.dias@butantan.gov.br

\section{Resumo}

Acidentes ofídicos ocorrem com frequência em áreas rurais no Brasil. Os relacionados a animais do gênero Crotalus não são frequentes, pois esses ofídios preferem locais secos e pedrosos e só atacam quando excitados. São facilmente identificados por possuírem um guizo. Seu veneno tem ação neurotóxica, miotóxica, coagulante e nefrotóxica. Não há necrose aparente no local da inoculação, provoca rabdomiólise sistêmica e por isso o animal apresenta mioglobinúria, paralisia motora e respiratória. A ação neurotóxica é principalmente mediada pela crotoxina, que atua nas terminações nervosas e inibe a liberação de acetilcolina. Causa bloqueio neuromuscular, promovendo paralisias motoras. A ação miotóxica produz lesões nas fibras musculares esqueléticas, liberando mioglobina e enzimas que serão excretadas na urina. A ação coagulante é similar a da trombina: promove o consumo de fatores de coagulação, promovendo incoagulabilidade sanguínea. Não apresenta trombocitopenia. Apesar das variações nos testes de coagulabilidade, as alterações hemorrágicas são discretas. Ocasiona lesão tubular indireta e direta devido à mioglobinúria. As manifestações clínicas em geral são tumefação e edema no local, dificuldade de preensão de alimento, alterações neurológicas, caracterizadas por "fáscies miastênica", evidenciadas por ptose palpebral, flacidez da musculatura da face e midríase. 0 efeito miotóxico causa mialgias de aparecimento precoce. Pode ter alteração na coloração da urina devido à mioglobinúria. Nos exames laboratoriais, observam-se aumento de creatina quinase (CK), aspartato amino transferase (AST) e variáveis níveis de leucocitose. 0 tratamento é baseado na administração de soro antiofídico, além de soro antitetânico e antibioticoterapia de amplo espectro. Fluidoterapia também é necessária, garantindo hidratação adequada, melhora na perfusão renal e suporte cardiovascular. Alguns animais podem desenvolver anemia devido à coagulopatia e diátese hemorrágica, sendo indicada transfusão sanguínea. 0 objetivo deste trabalho é relatar o caso de acidente 
ofídico causado por serpente do gênero Crotalus em equino na fazenda São Joaquim, Instituto Butantan. Foi atendido na sede da Fazenda São Joaquim, em janeiro de 2017, um equino, macho, SRD, 9 anos, pertencente à tropa produtora de plasma escorpiônico. 0 animal estava isolado no pasto. À inspeção, apresentou dificuldade de deambulação, redução acentuada na fase de elevação nos membros posteriores, arrastando as pinças no solo e dificuldade em manter o equilíbrio. Estava apático, com edema evidente em região de focinho e lábios, hiperemia e edema em mucosa do lábio inferior (possível local da picada), ptose palpebral bilateral, diminuição dos reflexos oculares, ptose labial e "Head Tilt". Inicialmente, foi administrado Ringer Lactato (IV) e Flunixin Meglumine (IM); em seguida, $100 \mathrm{ml}$ de soro anticrotálico foram diluídos em $1 \mathrm{~L}$ de glicose 5\% e administrados (IV) para o tratamento. À micção, apresentou colúria. Possuía dificuldade na preensão, mastigação e deglutição. No exame laboratorial, apresentou leucocitose acentuada, aumento expressivo de AST e ureia. A terapia complementar foi composta de fluidoterapia com solução fisiológica 0,9\%, Ringer Lactato e glicose 5\% (BID, IV), Flunixin Meglumine (TID, IM) e Ceftiofur (SID, IM). 0 animal foi monitorado durante a recuperação e apresentou melhora significativa, com remissão dos sinais clínicos, retorno gradual dos reflexos oculares e melhora na coordenação motora, urina normocorada, além de melhora nos exames laboratoriais. Desta forma, o mesmo recebeu alta. Corroborando com a literatura, o paciente apresentou alterações neurotóxicas, miotóxicas e nefrotóxicas. 0 quadro clínico e histórico do local levou a um diagnóstico presuntivo de acidente ofídico crotálico. A resposta ao soro específico foi efetiva, ratificando a suspeita clínica. A rápida identificação e instituição de tratamento são, portanto, de suma importância em casos de acidentes ofídicos.

Palavras-chave: Crotálico. Veneno. Neurotóxico. 